\section{In this issue - February 2020}

\author{
Serge Savary ${ }^{1}$
}

Published online: 14 January 2020

(C) International Society for Plant Pathology and Springer Nature B.V. 2020

The February 2020 Issue of Food Security includes 13 articles.

The first article, "Smallholder food storage dynamics and resilience", is a conceptual contribution to the dynamics of food storage by households. The analysis provides insights on this dynamics and its relations with the occurrence of food shortages. The work demonstrates the value of high frequency data collection to identify food security thresholds. This can have, in turn, considerable vaule in predicting food shortages at a fine spatial scale.

The second article, "Impacts of Smallholder Agricultural Adaptation on Food Security Evidence from Africa, Asia, and Central America ", is an analysis on a very large sample of 5159 households across the world (19 countries) of the impacts of adaptation strategies to environmental changes on household welfare. Two environmental changes are considered: physical (climate change) and economical (market conditions). The analysis demonstrate a key interaction: while adaptation to climate change alone does not seem to improve food security, adaptation to both climate and market changes generates 96 additional days of food security. This appears to be an exciting finding, showing the interactions between the socio-economic and physical determinants of food security.

The third article, "Beyond the risks to food availability linking climatic hazard vulnerability with the food access of delta-dwelling households ", considers food security in a key delta region of the world, Ganges-Brahmaputra- Meghna (GBM) delta in Bangladesh. The analysis suggests that adaptive capacity, measured as a function of household asset endowments, is more important in explaining food access than the exposure-sensitivity to flood itself.

Serge Savary

serge.savary@inra.fr

1 Institut National de la Recherche Agronomique, INRA, Auzeville, France
The fourth article "A model-based exploration of farmhousehold livelihood and nutrition indicators to guide nutrition-sensitive agriculture interventions", demonstrates the use of a farm household model to capture household nutrition and production diversity. The analysis allows to address three questions: (1) are the crops identified in a participatory process contribute to satisfying household dietary requirements?; (2) does this choice improve household livelihoods (in terms of, e.g., leisure time and dispensable budget)?; and (3) what is the contribution of home-garden diversification towards satisfying household dietary requirements? The analysis demonstrates that farm-household models can facilitate anticipating the effects (positive or negative) of agricultural interventions on nutrition and the environment. These models also can help identifying trade-offs and additional interventions.

The causes for yield variability for a major food crop are analysed in a fifth article, "Unravelling the variability and causes of smallholder maize yield gaps in Ethiopia". The study involves stochastic frontier analysis and concepts of production ecology to estimate efficient yields, the efficiency yield gap and the resource yield gap.

The sixth article, " Food security impacts of industrial crop production in sub-Saharan Africa: a systematic review of the impact mechanisms ", deals with "industrial crops", that is to say, crops which are grown for industrial purposes. The impacts of industrial crops on food security are addressed in sub-Saharan Africa. The analysis of this systematic review allows identifying priority policy to improve the food security outcomes of industrial crop production.

The seventh article, " How the choice of food security indicators affects the assessment of resilience - an example from northern Ethiopia “, addresses a methodological aspect of the assessment of food security. The article shows that the assessment of household food security is highly sensitive to decisions that are made in the process of its measurement.

The eighth article, "Weather index insurance, agricultural input use, and crop productivity in Kenya", addresses 
the fact that climate uncertainty leads farmers to limit inputs, and therefore climate risks, which in turn limits crop performances. The article explores the value of crop insurances and conditions to their implementation, and concludes that upscaling insurance programs may help to spur agricultural development in the small farm sector.

The ninth article, "Overcoming the dependent variable problem in studying food policy", addresses the status of food policies amongst policy components. The analysis considers four dimensions along which food policy outputs may differ: (i) policy scope, (ii) targeting of policy efforts, (iii) type of policy instruments applied and how these are calibrated, and (iv) integration of the various components of the policy complex. According to these dimensions, individual food policies may be characterised and compared across countries and time. Comparing and tracking the development of food policy along these dimensions would enable addressing follow-up questions about food policy impacts.

In the tenth article, "Intertemporal evaluation of household food security and its determinants: Evidence from Rwanda", the dynamics of household food security is analysed in Rwanda. The study shows the volatility of the food security status of households, especially in relation with agricultural seasons, and its dependence towards other factors such as household socio-demographic characteristics, household assets, income diversification, and location of the household dwelling.

Remittances from abroad has become an important topic in food security literature. The eleventh article, "International migration, remittance and food security during food crises: The case study of Nigeria ", shows that remittance is valuable in meeting both short and long-term food security, and is particularly important for female-headed households who are more vulnerable to food insecurity.

The twelfth and last article of this issue, The contribution of 'chitoumou', the edible caterpillar Cirina butyrospermi, to the food security of smallholder farmers in southwestern Burkina Faso, is a contribution to the theme of edible insects, and illustrates the value of edible insects to food security. 